\title{
Positive airway pressure therapy adherence for obstructive sleep apnea during the COVID-19 pandemic
}

\author{
Chatkarin Tepwimonpetkun $^{1,2} \cdot$ Dittapol Muntham $^{2,3} \cdot$ Pijitra Suppasawatgul $^{4} \cdot$ Naricha Chirakalwasan $^{1,2,5} \mathbb{C}$
}

Received: 10 June 2021 / Revised: 30 September 2021 / Accepted: 5 October 2021 / Published online: 19 October 2021

(c) The Author(s), under exclusive licence to Springer Nature Switzerland AG 2021

\begin{abstract}
Purpose Positive airway pressure (PAP) adherence is a significant issue among patients with obstructive sleep apnea (OSA). However, the data are limited regarding PAP adherence during the current COVID-19 pandemic.

Methods A cross-sectional study was conducted between February and October 2020 at the Excellence Center for Sleep Disorders, King Chulalongkorn Memorial Hospital, Bangkok, Thailand. Patients with ongoing PAP-treated OSA were recruited. Data on PAP adherence before and during the COVID-19 pandemic were collected. Furthermore, pre-test and post-test questionnaires on knowledge on COVID-19, OSA, and PAP before and after tele-education were also evaluated.

Results Of a total 156 patients, the majority had severe OSA (72\%). By self-report, there was no significant difference in PAP usage in hours per day before compared to during the pandemic $(p=0.45)$, though in a subgroup with highest educational attainment (degree higher than bachelor's), PAP usage did increase during the pandemic (mean difference $0.23 \pm 0.10$; 95\% CI $0.02-0.40, p=0.03$ ). However, objective PAP usage data demonstrated a trend towards increased usage comparing before and during the pandemic $(4.64 \pm 1.49$ vs $5.12 \pm 1.41$; mean difference $0.48 \pm 1.33$; $95 \%$ CI $0.13-10.90, p=0.12)$. Basic knowledge was significantly improved after tele-education $(p<0.001)$.

Conclusion By objective data, there was a trend towards increased PAP usage during the COVID-19 pandemic for the entire group. In a subgroup of patients with highest educational attainment, PAP adherence increased by self-report. Tele-education appeared to improve knowledge on COVID-19, OSA, and PAP usage.
\end{abstract}

Keywords Positive airway pressure compliance $\cdot$ Obstructive sleep apnea $\cdot$ COVID-19

Naricha Chirakalwasan

narichac@hotmail.com

1 Division of Pulmonary and Critical Care Medicine, Department of Medicine, Faculty of Medicine, Chulalongkorn University, 1873 Rama IV Road, Pathum Wan, Bangkok 10330, Thailand

2 Excellence Center for Sleep Disorders, Thai Red Cross Society, King Chulalongkorn Memorial Hospital, Bangkok, Thailand

3 Section for Mathematics, Faculty of Science and Technology, Rajamangala University of Technology Suvarnabhumi, Phranakhon Si Ayutthaya, Thailand

4 Faculty of Communication Arts, Chulalongkorn University, Bangkok, Thailand

5 Sleep Society of Thailand, Bangkok, Thailand

\section{Introduction}

Obstructive sleep apnea (OSA) is a common disorder in the Thai population. The overall prevalence is $11 \%, 15 \%$ in men and $6 \%$ in women [1]. The prevalence approximates the overall global prevalence [2]. Untreated OSA has been shown to be associated with multiple health consequences including depression, cardiovascular diseases, insulin resistance, metabolic syndrome, and excessive daytime sleepiness [3-6]. Furthermore, untreated OSA can impair quality of life and increase the likelihood of accidents [3]. Positive airway pressure (PAP) therapy remains the gold standard treatment [3]. Theoretically, PAP therapy should reduce the aforementioned health consequences. Previous studies have demonstrated a dose response curve for the effect of PAP therapy on cardiovascular outcomes, memory, daytime function, and daytime sleepiness [7-10]. Research over the past 20 years has demonstrated overall PAP adherence of approximately 25 to $50 \%$ [11]. Characteristics of patients 
nonadherent to PAP include inability to define risks associated with OSA, few outcome expectations, and a poor patient-doctor relationship [12].

However, the data are limited regarding PAP adherence during the current COVID-19 pandemic. COVID-19 is known to be transmitted by direct contact and respiratory droplets [13-15]. The American Academy of Sleep Medicine (AASM) [16] has recommended that PAP therapy continue to be used during the pandemic but in separate bedroom from other household members. This recommendation is based on a previous study which demonstrated increased aerosol transmission of COVID-19 with the use of a nebulizer [17]. Thus, using PAP may increase the risk of the transmission of COVID-19 among family members due to aerosol generation from positive pressure. Cessation of PAP therapy during the pandemic should be assessed individually by considering the risk of infection of the household weighed against the benefit of the treatment. If the decision is to stop PAP therapy, other treatment modalities for OSA might be considered such as oral appliance therapy and/or positional therapy. Mask decontamination and PAP maintenance during COVID-19 should follow recommendation from the US Centers for Disease Control and Prevention and instructions from the PAP supplier. General suggestions are to clean the mask pieces in direct facial contact with gentle soap and warm water, to avoid direct exposure of mask and accessories to the sunlight, and not to use alcohol for cleaning. In case of comorbid COVID-19 and OSA, it is recommended to change the PAP filter after recovery from COVID-19 [18, 19].

This current pandemic is a unique circumstance which may cause doubt regarding the safety of PAP usage among patients with OSA. This study aimed to evaluate the difference in PAP usage among patients with OSA before and during the COVID-19 pandemic and the effect of tele-education on PAP adherence.

\section{Materials and methods}

\section{Study design}

The study was conducted using a cross-sectional design to determine the effect of the COVID-19 pandemic on adherence to PAP therapy in patients with OSA and to determine the effect of tele-education on the basic knowledge about COVID-19, OSA, and PAP therapy.

\section{Participants}

The study was conducted between February 2020 and October 2020. A total of 283 participants, aged $18-70$ years with OSA treated with PAP therapy and followed up at the
Excellence Center for Sleep Disorders, King Chulalongkorn Memorial Hospital, Thai Red Cross Society, Bangkok, Thailand, were invited to participate in this study. Patients with other sleep disorders such as restless legs syndrome, narcolepsy, idiopathic hypersomnolence, or insomnia were excluded. Total of 156 participants completed the pre-test and post-test questionnaires. The pre-test questionnaire included baseline characteristics, severity of OSA, type of PAP interface, use of humidification, PAP usage in days per week and PAP usage in hours per day before and during the COVID-19 pandemic. The questionnaire also included a rating scale for basic knowledge about OSA, COVID-19, and PAP therapy. Before completing the post-test questionnaire, participants were instructed to watch a tele-education video. Tele-education provided basic knowledge about OSA, COVID-19, and PAP therapy. The post-test questionnaire also including a rating scale for basic knowledge about OSA, COVID-19, and PAP therapy was administered after teleeducation. The following link is the tele-education video used in the study. https://sst.or.th/sleep/\%e0\%b9\%82\%e0\% b8\%a3\%e0\%b8\%84-osa-\%e0\%b8\%81\%e0\%b8\%b1\%e0\% b8\%9a\%e0\%b8\%a0\%e0\%b8\%b2\%e0\%b8\%a7\%e0\%b8\%b0\% e0\%b9\%80\%e0\%b8\%aa\%e0\%b8\%b5\%e0\%b9\%88\%e0\%b8\% a2\%e0\%b8\%87-covid-19/

\section{Primary and secondary outcomes}

The primary outcome was the difference of PAP adherence among OSA patients before and during COVID-19 pandemic. The secondary outcomes included factors that determined PAP adherence before and during the COVID-19 pandemic, basic knowledge of OSA, COVID-19, and PAP therapy, and the benefits of tele-education on improving the knowledge. The period to determine PAP adherence before the COVID-19 pandemic was 6 months before 26 February 2020, the date of Thailand's national pandemic announcement (26 August 2019 to 26 February 2020).

\section{Statistical analysis}

A power analysis was conducted using the data from a previous study. The predicted sample size of 156 patients would provide a two-sided alpha level of 0.05 and an $80 \%$ power to detect a mean difference of $2.5 \mathrm{~h}$ per night of CPAP usage comparing usage before and during COVID-19 pandemic. This estimation was based on an assumption of loss to follow-up of an approximately $10 \%$. The statistical analysis included descriptive statistics for descriptive data. Continuous variables were reported as mean and standard deviation for normally distributed data. The primary outcome was PAP usage in days per week and in hours per day before and during the pandemic using a paired $t$-test with a threshold value of $p<0.05$. Comparisons of the basic knowledge 
about COVID-19, OSA, and PAP therapy before and after tele-education were conducted using paired $t$-tests. Pearson's correlation was used to determine the correlation between self-reported PAP adherence and machine-reported PAP adherence. The statistical analysis was performed using STATA version 14 (StataCorp College Station, TX, USA). This study was approved by the ethics committee and registered at www.clinicaltrials.in.th (\#TCTR20210202005). This research was financially supported by the Ratchadaphiseksomphot Endowment Fund of Chulalongkorn University.

\section{Results}

Initially there were 283 participants in this study. All participants completed the pre-test questionnaire before watching the tele-education video. After watching the tele-education video, there were 156 participants $(55 \%)$ who completed the post-test questionnaire. The mean duration for OSA diagnosis was $3.2 \pm 1.8$ years. The average age of participants was 58.9 years \pm 13.7 . The majority of participants had severe OSA. Baseline demographic and clinical characteristics are shown in Table 1.

There was no statistically significant difference in selfreported PAP adherence before and during COVID-19 pandemic for days used per week $(5.7 \pm 1.8$ vs $5.6 \pm 2.0$, respectively: $95 \% \mathrm{CI}-0.14-0.31, p=0.47)$. There was no statistically significant difference in self-reported PAP usage in hours per day before and during COVID-19 (5.7 \pm 1.9 vs $5.7 \pm 2.1$, respectively: $95 \%$ CI $-0.15-0.32, p=0.45)$. When adjusting for age, sex, and OSA severity, there was no statistically significant difference in PAP adherence comparing before and during the pandemic. Interestingly, in a subgroup with highest educational attainment (degree higher than bachelor's), self-reported PAP usage in hours per day was higher during the pandemic compared to before (mean difference $0.23 \pm 0.10 ; 95 \%$ CI $0.02-0.40, p=0.03$ ), as shown in Table 2.

Downloaded PAP machine data were collected in 21 participants. There was no statistically significant difference for percentage of days used before and during the pandemic $(82.3 \pm 17.1$ vs $81.4 \pm 22.9$, respectively: mean difference $0.98 \pm 5.87 ; 95 \% \mathrm{CI}-11.26-13.22, p=0.87)$. Concurrent with self-reported PAP usage, there was a trend towards increase in PAP usage in hours per day comparing before and during the pandemic $(4.6 \pm 1.5$ vs $5.1 \pm 1.4$ (mean difference $0.48 \pm 1.33$; $95 \%$ CI $0.13-10.9, p=0.12$ )), as shown in Table 3.

There was significant moderate correlation between selfreport PAP adherence and machine report PAP adherence in terms of usage day per week and machine report on percentage usage day before COVID-19 outbreak $(r=0.58$, $p=0.006$ ), usage hour per day before COVID-19 outbreak
Table 1 Baseline demographic and clinical characteristics

\begin{tabular}{|c|c|c|}
\hline & & $N(\%)$ \\
\hline \multirow[t]{3}{*}{ Age (years) } & $<30$ & $16(10.3)$ \\
\hline & $30-60$ & $87(55.8)$ \\
\hline & $>60$ & $53(34.0)$ \\
\hline \multirow[t]{2}{*}{ Sex } & Male & $106(68.0)$ \\
\hline & Female & $50(32.1)$ \\
\hline \multirow[t]{3}{*}{ OSA severity } & Mild & $10(6.4)$ \\
\hline & Moderate & $34(21.8)$ \\
\hline & Severe & $112(71.8)$ \\
\hline \multirow[t]{3}{*}{ Education } & Under-graduation & $24(15.4)$ \\
\hline & Bachelor's & $84(53.9)$ \\
\hline & Post-bachelor's & $48(30.8)$ \\
\hline \multirow[t]{9}{*}{ Co-morbidity } & Hypertension & $67(43.0)$ \\
\hline & Dyslipidemia & $66(42.3)$ \\
\hline & Diabetes mellitus & $34(21.8)$ \\
\hline & Fatty liver disease & $30(19.2)$ \\
\hline & Heart disease & $10(6.4)$ \\
\hline & Thyroid disease & $7(4.5)$ \\
\hline & Parkinson's disease & $6(3.9)$ \\
\hline & Kidney disease & $5(3.2)$ \\
\hline & Asthma & $4(2.6)$ \\
\hline \multirow[t]{2}{*}{ Humidification } & Yes & $60(38.5)$ \\
\hline & No & $96(61.5)$ \\
\hline \multirow{2}{*}{$\begin{array}{l}\text { Humidification during } \\
\text { COVID-19 }(\mathrm{N}=60)\end{array}$} & Yes & $53(88.3)$ \\
\hline & No & $7(11.7)$ \\
\hline \multirow[t]{3}{*}{ Mask type } & Pillow & $8(5.1)$ \\
\hline & Nasal & $130(83.3)$ \\
\hline & Oro-nasal & $18(11.5)$ \\
\hline
\end{tabular}

(total day) ( $r=0.50, p=0.02)$, usage hour per day during COVID-19 pandemic (total day) $(\mathrm{r}=0.57, \mathrm{p}=0.01)$, and usage hour per day during COVID-19 pandemic (day use) $(r=0.55, p=0.01)$ as shown in Table 4.

Basic knowledge on OSA and COVID-19 was significantly improved after tele-education $(p<0.001)$. Knowledge on PAP usage was also significantly improved $(p<0.001)$ as shown in Table 5.

\section{Discussion}

Self-reported data demonstrated no significant difference in PAP adherence before and during the COVID-19 pandemic. The PAP usage data were reported as number of days per week and number of hours per day. A previous study showed the median usage of PAP therapy in OSA to be $4.7 \pm 2.1 \mathrm{~h}$ per night [8]. However, the current study demonstrated PAP usage hours per day before COVID-19 pandemic to be $5.7 \pm 1.9 \mathrm{~h}$ and during COVID-19 pandemic to be $5.7 \pm 2.1$ which were more than that reported in the previous study. 
Table 2 Primary outcome, self-reported adherence

\begin{tabular}{|c|c|c|c|c|c|c|c|}
\hline & & \multicolumn{2}{|c|}{ Usage day per week (mean \pm S.D.) } & \multirow{2}{*}{$\begin{array}{l}\text { Mean diff } \pm \text { S.D. } \\
\text { (95\% CI, } p \\
\text { value) (before } \\
\text { COVID-during } \\
\text { COVID) }\end{array}$} & \multicolumn{2}{|c|}{ Usage hour per day } & \multirow{2}{*}{$\begin{array}{l}\text { Mean diff } \pm \text { S.D. } \\
\text { (95\% CI, } p \text { value) } \\
\text { (before COVID- } \\
\text { during COVID) }\end{array}$} \\
\hline & & $\begin{array}{l}\text { Before COVID- } \\
19\end{array}$ & $\begin{array}{l}\text { During COVID- } \\
19\end{array}$ & & $\begin{array}{l}\text { Before COVID- } \\
19\end{array}$ & $\begin{array}{l}\text { During COVID- } \\
19\end{array}$ & \\
\hline $\begin{array}{l}\text { All patients } \\
(N=156)\end{array}$ & & $5.7 \pm 1.8$ & $5.6 \pm 2.0$ & $\begin{array}{l}0.08 \pm 1.43 \\
(-0.14-0.31 \\
p=0.47)\end{array}$ & $5.7 \pm 1.9$ & $5.7 \pm 2.1$ & $\begin{array}{l}0.09 \pm 1.49 \\
(-1.45-0.32 \\
p=0.45)\end{array}$ \\
\hline \multicolumn{8}{|c|}{ Subgroup analysis } \\
\hline \multirow[t]{3}{*}{ Age (years) } & $<30$ & $5.6 \pm 2.1$ & $6.1 \pm 1.5$ & $\begin{aligned} & 0.44 \pm 1.75 \\
(-1.37-0.59 & \\
p= & 0.33)\end{aligned}$ & $7.0 \pm 2.4$ & $7.5 \pm 1.6$ & $\begin{array}{l}-0.5 \pm 2.28 \\
(-1.72-0.72 \\
p=0.39)\end{array}$ \\
\hline & $30-59$ & $5.6 \pm 1.8$ & $5.4 \pm 2.2$ & $\begin{array}{l}0.25 \pm 1.37 \\
(-0.04-0.54 \\
p=0.09)\end{array}$ & $5.7 \pm 1.8$ & $5.5 \pm 2.2$ & $\begin{array}{l}0.21 \pm 0.13 \\
(-0.05-0.47 \\
p=0.12)\end{array}$ \\
\hline & $\geq 60$ & $5.7 \pm 1.7$ & $5.8 \pm 1.8$ & $\begin{array}{l}-0.04 \pm 1.39 \\
(-0.42-0.34 \\
p=0.84)\end{array}$ & $5.5 \pm 1.7$ & $5.4 \pm 1.8$ & $\begin{array}{l}0.08 \pm 1.58 \\
(-0.36-0.51, \\
p=0.73)\end{array}$ \\
\hline \multirow[t]{2}{*}{ Sex } & Male & $5.7 \pm 1.8$ & $5.6 \pm 2.0$ & $\begin{array}{l}0.04 \pm 1.29 \\
(-0.21-0.29 \\
p=0.76)\end{array}$ & $5.8 \pm 2.0$ & $5.8 \pm 2.2$ & $\begin{array}{l}0.03 \pm 1.46 \\
(-0.25-0.31 \\
p=0.84)\end{array}$ \\
\hline & Female & $5.6 \pm 1.78$ & $5.4 \pm 2.1$ & $\begin{array}{l}0.18 \pm 1.67 \\
(-0.30-0.66 \\
p=0.45)\end{array}$ & $5.6 \pm 1.6$ & $5.4 \pm 2.0$ & $\begin{array}{l}0.22 \pm 1.54 \\
(-0.22-0.66 \\
p=0.32)\end{array}$ \\
\hline \multirow[t]{3}{*}{ OSA severity } & Mild & $6.2 \pm 1.5$ & $6.2 \pm 1.3$ & $\begin{array}{l}0 \pm 0.47(-0.34- \\
0.34, p=1)\end{array}$ & $6.7 \pm 2.0$ & $6.8 \pm 1.7$ & $\begin{array}{l}-0.10 \pm 0.57 \\
(-0.51-0.31 \\
p=0.60)\end{array}$ \\
\hline & Moderate & $5.6 \pm 1.9$ & $5.1 \pm 2.5$ & $\begin{array}{r}0.5 \pm 1.85 \\
(-0.14-1.14 \\
p=0.12)\end{array}$ & $5.3 \pm 1.7$ & $5.0 \pm 2.2$ & $\begin{array}{l}0.29 \pm 1.40 \\
(-0.20-0.78 \\
p=0.23)\end{array}$ \\
\hline & Severe & $5.6 \pm 1.8$ & $5.7 \pm 1.9$ & $\begin{array}{l}-0.04 \pm 1.31 \\
(-0.28-0.21 \\
p=0.77)\end{array}$ & $5.8 \pm 2.0$ & $5.8 \pm 2.0$ & $\begin{array}{l}0.04 \pm 1.57 \\
(-0.25-0.34 \\
p=0.76)\end{array}$ \\
\hline \multirow[t]{3}{*}{ Education } & $\begin{array}{l}\text { Under-gradu- } \\
\text { ation }\end{array}$ & $5.3 \pm 2.1$ & $5.3 \pm 2.1$ & $\begin{array}{l}-0.04 \pm 2.18 \\
(-0.96-0.88 \\
p=0.93)\end{array}$ & $6.1 \pm 2.2$ & $6.1 \pm 2.3$ & $\begin{array}{l}-0.04 \pm 2.67 \\
(-1.04-0.96 \\
p=0.93)\end{array}$ \\
\hline & Bachelor & $5.8 \pm 1.6$ & $5.6 \pm 2.0$ & $\begin{array}{l}\quad 0.26 \pm 1.46 \\
(-0.05-0.58, \\
p=0.10)\end{array}$ & $5.8 \pm 1.8$ & $5.5 \pm 2.1$ & $\begin{array}{l}0.31 \pm 1.48 \\
(-0.01-0.63 \\
p=0.06)\end{array}$ \\
\hline & Post-graduation & $5.6 \pm 2.1$ & $5.7 \pm 1.9$ & $\begin{array}{l}-0.17 \pm 0.69 \\
(-0.37-0.03 \\
p=0.10)\end{array}$ & $5.5 \pm 2.0$ & $5.7 \pm 1.9$ & $\begin{array}{l}-0.23 \pm 0.69 \\
(-0.43-0.03 \\
p=0.03)^{*}\end{array}$ \\
\hline
\end{tabular}

*Statistically significant difference

A retrospective study from the USA on the effect of the novel coronavirus disease on treatment adherence and sleep duration in patients with OSA treated with PAP showed no difference in hours of PAP use or self-reported sleep duration $(N=123$, before COVID-19 $6.0 \pm 1.9 \mathrm{~h}$ per day, after COVID-19 $5.9 \pm 2.1 \mathrm{~h}$ per day) [20]. The aforementioned

Table 3 Machine reported adherence $(N=21)$

\begin{tabular}{lcccc}
\hline & $\begin{array}{l}\text { Before COVID-19, } \\
\text { mean } \pm \text { S.D }\end{array}$ & $\begin{array}{l}\text { During COVID-19, } \\
\text { mean } \pm \text { S.D }\end{array}$ & $\begin{array}{l}\text { Mean diff } \pm \text { S.D. (before } \\
\text { COVID-after COVID) }\end{array}$ & 95\% CI, $p$ value \\
\hline Percentage of days used & $82.3 \pm 17.1$ & $81.4 \pm 22.9$ & $0.98 \pm 26.88$ & $-11.26-13.22, p=0.87$ \\
Percentage of days $>4 \mathrm{~h}$ & $70.3 \pm 24.3$ & $74.4 \pm 20.8$ & $-4.08 \pm 17.89$ & $-12.23-4.06, p=0.31$ \\
Average hours used per day & $4.6 \pm 1.5$ & $5.1 \pm 1.4$ & $-0.48 \pm 1.33$ & $-1.09-0.13, p=0.12$ \\
Average hours on days used & $5.6 \pm 1.5$ & $5.9 \pm 1.3$ & $-0.19 \pm 1.03$ & $-0.69-0.31, P=0.43$ \\
\hline
\end{tabular}


Table 4 Correlation between self and machine reported on PAP adherence $(N=21)$

\begin{tabular}{lllll}
\hline & & Mean \pm S.D & $p$ value & r \\
\hline Before COVID-19 & Patient self-report on usage, days per week & $5.7 \pm 1.4$ & $0.006^{*}$ & 0.58 \\
& Machine report on usage, days per week & $82.3 \pm 17.0$ & & \\
& Patient self-report on usage, hours per day (all days) & $5.5 \pm 1.5$ & $0.02^{*}$ & 0.50 \\
& Machine report on usage, hours per day (all days) & $4.6 \pm 1.5$ & & \\
& Patient self-report on usage, hours per day (on days use) & $5.4 \pm 1.5$ & 0.28 & 0.27 \\
& Machine report on usage, hours per day (on days used) & $5.9 \pm 1.2$ & & \\
During COVID-19 & Patient self-report on usage, days per week & $5.9 \pm 1.8$ & 0.32 & 0.23 \\
& Machine report on usage, days per week & $81.4 \pm 22.9$ & & \\
& Patient self-report on usage, hours per day (all days) & $5.5 \pm 1.9$ & $0.01^{*}$ & 0.57 \\
& Machine report on usage, hours per day (all days) & $5.1 \pm 1.4$ & & \\
& Patient self-report on usage, houra per day (on days used) & $5.3 \pm 2.0$ & $0.01^{*}$ & 0.55 \\
& Machine report on usage, hours per day (on days used) & $5.9 \pm 1.3$ & & \\
\hline
\end{tabular}

*Statistically significant difference study was similar to our study which had the average age of participants of $63.5 \pm 13.9$ years, male predominant (55\%), and predominantly severe OSA $(60 \%)$.

Interestingly, in a subgroup with highest educational attainment (degree higher than bachelor's degree), PAP usage hours per day was higher during COVID-19 pandemic (mean difference $0.23 \pm 0.1 ; 95 \%$ CI $0.02-0.4, p=0.03$ ). This difference was not observed in the objective data. The limited number of patients with objective data (21 patients) likely caused this analysis to be underpowered. However, the objective PAP usage report also demonstrated a trend towards increase in PAP usage hours per day comparing before and during COVID-19 pandemic. Similar to our findings, Saraç $\mathrm{S}$ et al. demonstrated that primary school education level was inversely related with PAP compliance (OR 0.3, 95\% CI 0.1-0.9; $p=0.036$ ) [21].

A study in France demonstrated the effect of the COVID19 national lockdown on objective adherence to CPAP assessed by telemonitoring in a cohort of 7,485 patients with OSA. The study showed $3.9 \%$ increase in adherence from a mean value of 386 min per night pre-COVID-19 to 401 min per night during lockdown $(p<0.001)$ [22]. Del Campo et al. also compared 3-month-PAP adherence before COVID-19 lockdown and 1 month after COVID-19 lock down in Spain. A total of 2,956 participants with a median age of 63 years (interquartile range 54-71 years of age) were included in the study and $77.7 \%$ were men. This study demonstrated improvement in PAP adherence from 75.1 to 79.5\% ( $p<0.0001)$ after COVID-19 lockdown irrespective of sex, age, and severity of OSA. However, the participants used only one brand of CPAP in the study [23]. In our study, there were different brands of CPAP utilized making the situation similar to a real world practice.

In our study, basic knowledge about OSA and COVID-19 were significantly improved after tele-education. Knowledge on PAP usage was also significantly improved. Hence, teleeducation appeared to improve COVID-19 knowledge, OSA knowledge, and PAP usage knowledge. A randomized control trial in Turkey showed that educational support improved the average PAP usage from $4.2 \pm 2.5 \mathrm{~h}$ per night in a standard support group to $5.2 \pm 2.1 \mathrm{~h}$ per night in an educational support group ( $p=0.027)$. The PAP adherence, defined by $4 \mathrm{~h} /$ night for $70 \%$ of all the nights, was $68.3 \%$ in the standard support group and $86.5 \%$ in the educational support group $(p=0.021)$ [21].

\section{Conclusion}

PAP adherence in patients with OSA during the COVID19 pandemic was significantly increased among a group with post-bachelor's education. Tele-education significantly improved general OSA knowledge, COVID-19 knowledge, and PAP knowledge.

Table 5 Knowledge before and after tele-education (Before score-After score)

\begin{tabular}{|c|c|c|c|c|c|}
\hline & $\begin{array}{l}\text { Before tele-educa- } \\
\text { tion (mean } \pm \text { S.D.) }\end{array}$ & $\begin{array}{l}\text { After tele-educa- } \\
\text { tion (mean } \pm \text { S.D.) }\end{array}$ & $\begin{array}{l}\text { Mean diff } \pm \text { S.D. (before } \\
\text { COVID-after COVID) }\end{array}$ & $95 \% \mathrm{CI}$ & $p$ value \\
\hline $\begin{array}{l}\text { Knowledge about OSA and COVID-19 } \\
(\text { total score }=4)\end{array}$ & $2.0 \pm 0.9$ & $3.0 \pm 0.8$ & $-0.97 \pm 0.96$ & -1.13 to -0.82 & $<0.001^{*}$ \\
\hline Knowledge about PAP (total score $=4$ ) & $2.6 \pm 0.9$ & $3.7 \pm 0.6$ & $-1.12 \pm 0.98$ & -1.27 to -0.96 & $<0.001^{*}$ \\
\hline
\end{tabular}

*Statistically significant difference 


\section{Study limitations}

Our study in Asia on PAP adherence in patients with OSA patients during COVID-19 pandemic yielded similar findings compared to previous reports conducted in other regions. There were two main limitations in our study. First, previous studies have demonstrated that self-reported PAP adherence may be overestimated compared to objective machinereported adherence in up to $35 \%$ [11]. Since most of the data were self-reported and only $14 \%$ machine-reported (objective downloaded data), results must be interpreted with caution. However, a moderate correlation was observed between selfreported and machine-reported data in our study. A second limitation in the current study was that we calculated the sample size from the expected difference of $2.5 \mathrm{~h}$ per day before and after the pandemic. As we did not demonstrate this degree of difference, the study may have been substantially underpowered.

Abbreviations PAP: Positive airway pressure; OSA: Obstructive sleep apnea; COVID-19: Coronavirus disease starting in 2019; AASM: American Academy of Sleep Medicine

Author contribution All authors contributed substantially to the study conception and design. All authors read and approved the final manuscript.

Funding This study was funded by Ratchadapiseksompotch Fund, Faculty of Medicine, Chulalongkorn University, grant number RA63/063.

Data availability Not applicable.

Code availability Not applicable.

\section{Declarations}

Ethics approval The Institutional Ethical Committee of Faculty of Medicine, Chulalongkorn University, Bangkok, Thailand, approved the study.

Informed consent Informed consent was obtained from all the participants.

Consent to participate Informed consent was obtained from all participants.

Consent for publications All the listed authors have agreed with the manuscript's content and gave explicit consent to submit.

Conflict of interest This study was done in collaboration with the Excellence Center for Sleep Disorders at King Chulalongkorn Memorial Hospital. CT, DM, PS, and NC have no potential conflict of interest.

\section{References}

1. Neruntarat C, Chantapant S (2011) Prevalence of sleep apnea in HRH princess Maha Chakri Srinthorn medical center. Thailand. Sleep and Breathing 15(4):641-648

2. Benjafield AV, Ayas NT, Eastwood PR, Heinzer R, Ip MS, Morrell MJ et al (2019) Estimation of the global prevalence and burden of obstructive sleep apnoea: a literature-based analysis. Lancet Respir Med 7(8):687-698

3. Patil SP, Ayappa IA, Caples SM, Kimoff RJ, Patel SR, Harrod CG (2019) Treatment of adult obstructive sleep apnea with positive airway pressure: an American Academy of Sleep Medicine clinical practice guideline. J Clin Sleep Med 15(2):335-343

4. Budhiraja R, Sharief I, Quan SF (2005) Sleep disordered breathing and hypertension. J Clin Sleep Med 1(04):401-404

5. Marin JM, Carrizo SJ, Vicente E, Agusti AG (2005) Longterm cardiovascular outcomes in men with obstructive sleep apnoea-hypopnoea with or without treatment with continuous positive airway pressure: an observational study. The Lancet 365(9464):1046-1053

6. Redline S, Yenokyan G, Gottlieb DJ, Shahar E, O'Connor GT, Resnick HE et al (2010) Obstructive sleep apnea-hypopnea and incident stroke: the sleep heart health study. Am J Respir Crit Care Med 182(2):269-277

7. Zimmerman ME, Arnedt JT, Stanchina M, Millman RP, Aloia MS (2006) Normalization of memory performance and positive airway pressure adherence in memory-impaired patients with obstructive sleep apnea. Chest 130(6):1772-1778

8. Weaver TE, Maislin G, Dinges DF, Bloxham T, George CF, Greenberg H et al (2007) Relationship between hours of CPAP use and achieving normal levels of sleepiness and daily functioning. Sleep 30(6):711-719

9. Yu J, Zhou Z, McEvoy RD, Anderson CS, Rodgers A, Perkovic V et al (2017) Association of positive airway pressure with cardiovascular events and death in adults with sleep apnea: a systematic review and meta-analysis. JAMA 318(2):156-166

10. Peker Y, Glantz H, Eulenburg C, Wegscheider K, Herlitz J, Thunström E (2016) Effect of positive airway pressure on cardiovascular outcomes in coronary artery disease patients with nonsleepy obstructive sleep apnea. The RICCADSA randomized controlled trial. Am J Respir Critic Care Med 194(5):613-20

11. Rotenberg BW, Murariu D, Pang KP (2016) Trends in CPAP adherence over twenty years of data collection: a flattened curve. J Otolaryngol Head Neck Surg 45(1):43

12. Sawyer AM, Gooneratne NS, Marcus CL, Ofer D, Richards KC, Weaver TE (2011) A systematic review of CPAP adherence across age groups: clinical and empiric insights for developing CPAP adherence interventions. Sleep Med Rev 15(6):343-356

13. Harapan H, Itoh N, Yufika A, Winardi W, Keam S, Te H et al (2020) Coronavirus disease 2019 (COVID-19): a literature review. J Infect Public Health 13(5):667-673

14. Huang C, Wang Y, Li X, Ren L, Zhao J, Hu Y et al (2020) Clinical features of patients infected with 2019 novel coronavirus in Wuhan. China The lancet 395(10223):497-506

15. Wang D, Hu B, Hu C, Zhu F, Liu X, Zhang J et al (2020) Clinical characteristics of 138 hospitalized patients with 2019 novel coronavirus-infected pneumonia in Wuhan. China Jama 323(11):1061-1069

16. (2020) COVID-19 mitigation strategies for sleep clinics and sleep centers https://aasm.org/covid-19-resources/covid-19-mitigationstrategies-sleep-clinics-labs. Accessed 27 April 2020

17. van Doremalen N, Bushmaker T, Morris DH, Holbrook MG, Gamble A, Williamson BN et al (2020) Aerosol and surface 
stability of SARS-CoV-2 as compared with SARS-CoV-1. N Engl J Med 382(16):1564-1567

18. (2020) COVID-19: FAQs for Sleep Clinicians. https://aasm.org/ covid-19-resources/covid-19-faq/. Accessed 7 April 2020

19. Infection Control Guidance for Healthcare Professionals about Coronavirus (COVID-19). https://www.cdc.gov/coronavirus/ 2019-ncov/hcp/infection-control.html?CDC_AA_refVal=https\% $3 \mathrm{~A} \% 2 \mathrm{~F} \% 2 \mathrm{Fwww} . c d c$. gov $\% 2$ Fcoronavirus\%2F2019-ncov\%2Finf ection-control\%2Findex.html. Accessed 24 April 2020

20. Batool-Anwar S, Omobomi OS, Quan SF (2020) Impact of the novel coronavirus disease on treatment adherence and sleep duration in patients with obstructive sleep apnea treated with positive airway pressure. J Clin Sleep Med 16(11):1917-1920

21. Saraç S, Afşar GÇ, Oruç Ö, Topçuoğlu ÖB, Saltürk C, Peker Y (2017) Impact of patient education on compliance with positive airway pressure treatment in obstructive sleep apnea. Med Sci Monit 23:1792
22. Attias D, Pepin JL, Pathak A (2020) Impact of COVID-19 lockdown on adherence to continuous positive airway pressure by obstructive sleep apnoea patients. Eur Respir J 56(1):2001607

23. del Campo F, López G, Arroyo CA, de Frutos JF, Crespo A, Cerezo-Hernández A et al (2020) Estudio de la adherencia al tratamiento con presión continua positiva en la vía aérea en pacientes con síndrome de apnea obstructiva del sueño en el confinamiento impuesto durante la pandemia de COVID-19. Arch Bronconeumol $56(12): 818$

Publisher's note Springer Nature remains neutral with regard to jurisdictional claims in published maps and institutional affiliations. 